\title{
Sobre o gênero Austrostelis Michener \& Griswold stat.n. (Hymenoptera, Megachilidae), com algumas modificações nomenclaturais ${ }^{1}$
}

\author{
Danúncia Urban ${ }^{2}$
}

\begin{abstract}
On the genus Austrostelis Michener \& Griswold stat.n. (Hymenoptera, Megachilidae), with some nomenclatural changes. The subgenus Hoplostelis (Austrostelis), proposed by Michener and Griswold (1994), is here raised up to the genus level: Austrostelis stat.n. The following nomenclatural changes are introduced: Austrostelis catamarcensis (Schrottky, 1909) comb.n. (= Dianthidium nudum Schrottky, 1909 syn.n. $=$ Stelis aliena Cockerell, 1919 syn.n. $=$ Stelis argentina Friese, 1925 syn.n. = Stelis magna Friese, 1925 syn.n.); Austrostelis iheringi (Schrottky, 1910) comb.n.; Austrostelis zebrata (Schrottky, 1905) comb.n. Lectotypes are designated for: Dianthidium catamarcense Schrottky, 1909, Dianthidium iheringi Schrottky, 1910, Dianthidium nudum Schrottky, 1909, and Dianthidium zebratum Schrottky, 1905. A key for species and illustrations are also provided.
\end{abstract}

KEY WORDS. Austrostelis, Anthidiinae, Megachilidae, taxonomy

GRISWOLD \& MichENER (1988) observaram que dentro do gênero Hoplostelis Dominique, 1898, havia dois grupos distintos de espécies que seriam: um formado por indivíduos robustos, o grupo bivittata, e o outro formado por indivíduos menores e mais delgados, o grupo aliena. As espécies do grupo aliena haviam sido colocadas previamente em Stelis Panzer, 1806, um gênero holártico. MicHENER \& GRISWOLD (1994) reconheceram que o grupo aliena possuía caracteres suficientes para sustentar o status de gênero mas preferiram considerá-lo apenas como um subgênero: Hoplostelis (Austrostelis). Concordando com o ponto de vista dos autores citados, Austrostelis é aqui elevado à categoria de gênero. Hoplostelis foi redescrito por MOURE \& URBAN (1994).

Não foram examinados espécimens de: Stelis bonaventura Friese, 1925 nem de Stelis flava Friese, 1925 arroladas por MICHENER \& GRISWOLD (1994) entre as espécies deste grupo. Segundo FrIESE (1925), S. bonaventura, de Buenos Aires, Argentina, tem o segundo tergo preto e S. flava, de Popayán, Colômbia, tem quase todo o abdomen amarelo. Não foi visto nenhum exemplar com estas características. Somente o exame do material-tipo permitirá esclarecer a posição taxonômica destas duas espécies.

1) Contribuição número 1096 do Departamento de Zoologia, Universidade Federal do Paraná.

2) Departamento de Zoologia, Universidade Federal do Paraná. Caixa Postal 19020, 81531-990 Curitiba, Paraná, Brasil. Bolsista do CNPq. 


\section{Austrostelis Michener \& Griswold stat.n.}

Hoplostelis (Austrostelis) Michener \& Griswold, 1994: 676.

Espécie tipo: Stelis aliena Cockerell, 1919 (= Dianthidium catamarcense Schrottky, 1909). Designação original.

Diagnose. Espécimens de tamanho pequeno (até $8 \mathrm{~mm}$ de comprimento), pontuação da cabeça e dorso do mesosoma como nos mesepisternos, nos tergos os pontos pouco menores. Mandíbulas sem fóvea ventro-basal e sem tubérculo dorsal, com duas carenas finas brilhantes na metade apical; carenas interalveolares fortes e laminadas, dispostas em arco e com o espaço entre as mesmas maior dorsalmente. Escutelo com lâminas translúcidas aos lados; carena pré-episternal na metade dorsal dos mesepisternos; pernas anteriores e medianas somente com uma projeção espiniforme no ápice da tíbia; base do propódeo com alvéolos retangulares quase tão longos como os flagelômeros. Primeiro tergo sem carena entre a declividade basal e face dorsal, apenas com uma área brilhante elevada. Machos com mandíbulas tridentadas, sétimo tergo curto, protuberante no disco e arqueado na margem; dois esternos basais longos, com pilosidade curta, terceiro e quarto com franja decumbente, quinto e sexto esternos com projeções laterais espiniformes e pilosidade semi-ereta voltada para o meio. Fêmeas com mandíbulas quadridentadas, sexto tergo tão longo como o anterior, com a margem reta, marcado por uma depressão profunda no terço distal e outra mais rasa subapical resultando uma dobra no tegumento.

Comentário. Os Hoplostelis têm porte maior, pontuação do mesoscuto e dos tergos muito fina quando comparada com a dos mesepisternos; fóvea ventro-basal nas mandíbulas; com carenas interalveolares divergentes dorsalmente; tergo basal com carena delimitando a declividade basal. Machos com projeções laterais espiniformes no sexto esterno. Mandíbulas das fêmeas profundamente modificadas e com tubérculo dorsal; o tergo distal em arco rebaixado.

\section{Austrostelis catamarcensis (Schrottky, 1909) comb.n.}

Figs 1-2

Dianthidium catamarcense Schrottky, 1909a: 218.

Dianthidium nudum Schrottky, 1909b: 269. Syn.n.

Hoplostelis (Austrostelis) nuda; Michener \& Griswold, 1994: 677.

Stelis aliena Cockerell, 1919: 27. Syn.n.

Hoplostelis (Austrostelis) aliena; Michener \& Griswold, 1994: 677.

Stelis argentina Friese, 1925: 37. Syn.n.

Hoplostelis (Austrostelis) argentina; Michener \& Griswold, 1994: 677.

Stelis magna Friese, 1925: 37. Syn.n.

Austrostelis é um nome feminino, razão da correção do nome específico.

Diagnose. Tegumento predominante preto. Cabeça amarelo-ferrugínea com desenhos pretos entre os alvéolos e a área ocelar e no clípeo. Mesoscuto com duas grandes máculas amarelas em U invertido, manchadas com ferrugíneo no ramo interno, esta cor preenchendo a figura em $\mathrm{U}$; axilas amarelas em contraste com o escutelo ferrugíneo-avermelhado. Tergos pretos, os dois basais castanho-averme- 
lhados nos lados; o primeiro com faixas laterais amarelo-pálidas e, do segundo ao quarto com quatro séries de nódoas ovaladas amarelo-pálidas em cada tergo.

Macho com o sexto tergo curto, menor que a metade do comprimento do anterior, protuberante no disco até junto aos esternos, nos flancos em forma de carena orlada com micro-tubérculos; sétimo fracamente bissinuoso pela presença de dois tubérculos carenados unidos medianamente; terceiro e quarto esternos com franja sedosa, os pêlos de tamanho uniforme.

O lectótipo macho de Dianthidium catamarcense, aqui designado, está depositado no Museu de Zoologia da Universidade de São Paulo. Tem as etiquetas: "Catamarca / III. 08 Bruch" "Dianthidium / catamarcense / o Schrottky" "Type" "Stelis / catamarcensis / (Schr.) / Det. J.S. Moure 1957" "Lectotypus". O exemplar tem o clípeo preto e grande área preta na fronte, nódoa discal ferrugínea na área supraclipeal e nódoa arredondada também ferrugínea junto ao ocelo mediano, faixa pós-ocelar ferrugínea unida às estrias amarelas paroculares e prolongada até o meio das genas; mesoscuto preto com as máculas em $U$ invertido fragmentadas e muito finas, com a base e os lados amarelos, o ramo discal ferrugíneo.

Lectótipo fêmea de Dianthidium nudum, aqui designado, com as etiquetas: "Catam[arca]" "Type", com a seguinte etiqueta colada na outra face: "Dianthidium/ nudum / Schrottky" "Stelis / nuda / Schr. / Det. J.S. Moure 1957" "102.235" "Lectotypus". Depositado no Museu de Zoologia da Universidade de São Paulo. O lectótipo tem faixa ferrugínea atrás dos ocelos só no vértice, nódoa amarela arredondada junto ao ocelo mediano e mesepisternos pretos; o mesoscuto com faixas basais amarelas curtas e pequenas estrias laterais finas também amarelas, sem desenhos em U invertido.

O holótipo de Stelis aliena encontra-se no United States National Museum of Natural History. Uma fêmea coletada em Rio Claro, São Paulo, foi comparada com o tipo por J. S. Moure; tem o mesmo padrão de colorido do holótipo: mancha amarelo-ocre no meio da fronte, levemente estrangulada junto ao ocelo; mesoscuto com as máculas em $U$ invertido com ferrugíneo entre os ramos do $U$, e finamente amarelas na base e nos lados.

Duas espécies descritas por FRIESE (1925), Stelis argentina e Stelis magna, respectivamente, macho de Tucumán, Argentina e fêmea de Jundiaí, São Paulo, com nódoas amarelas nos tergos, são colocadas agora na sinonímia de $A$. catamarcensis. Ao descrever Stelis magna, Friese sugeriu que talvez fosse uma fêmea de Stelis argentina.

Variações. Fêmeas de La Rioja (Argentina) e de Rio Claro (Brasil) com as genas inteiramente, ou somente na metade dorsal, ferrugíneas; foram vistos também, exemplares com os mesepisternos pretos ou com nódoa ferrugínea discal e com redução da mancha amarela do meio da fronte. Machos, coletados em Buenos Aires, com o clípeo ferrugíneo orlado com preto ou com o clípeo preto e com faixas laterais muito finas ferrugíneo-acastanhadas, sub-marginais. Um macho, coletado em Catamarca, com o tegumento da cabeça bastante diferente do lectótipo, com o clípeo, área supraclipeal e estria no meio da fronte ferrugíneos, o preto reduzido às proximidades dos alvéolos e entre os ocelos; as máculas em $U$ invertido do mesoscuto com castanho-ferrugíneo entre os ramos do U; os dois tergos basais com 
áreas ruivas látero-ventrais. Sete machos, coletados em São Paulo, Minas Gerais e Goiás, com grande parte da cabeça ferrugínea, passando a amarela no meio da fronte e nas paroculares, e as áreas pretas reduzidas a duas estrias entre o clípeo e os ocelos laterais, unidas no vértice ou curtas e somente nas proximidades dos alvéolos.
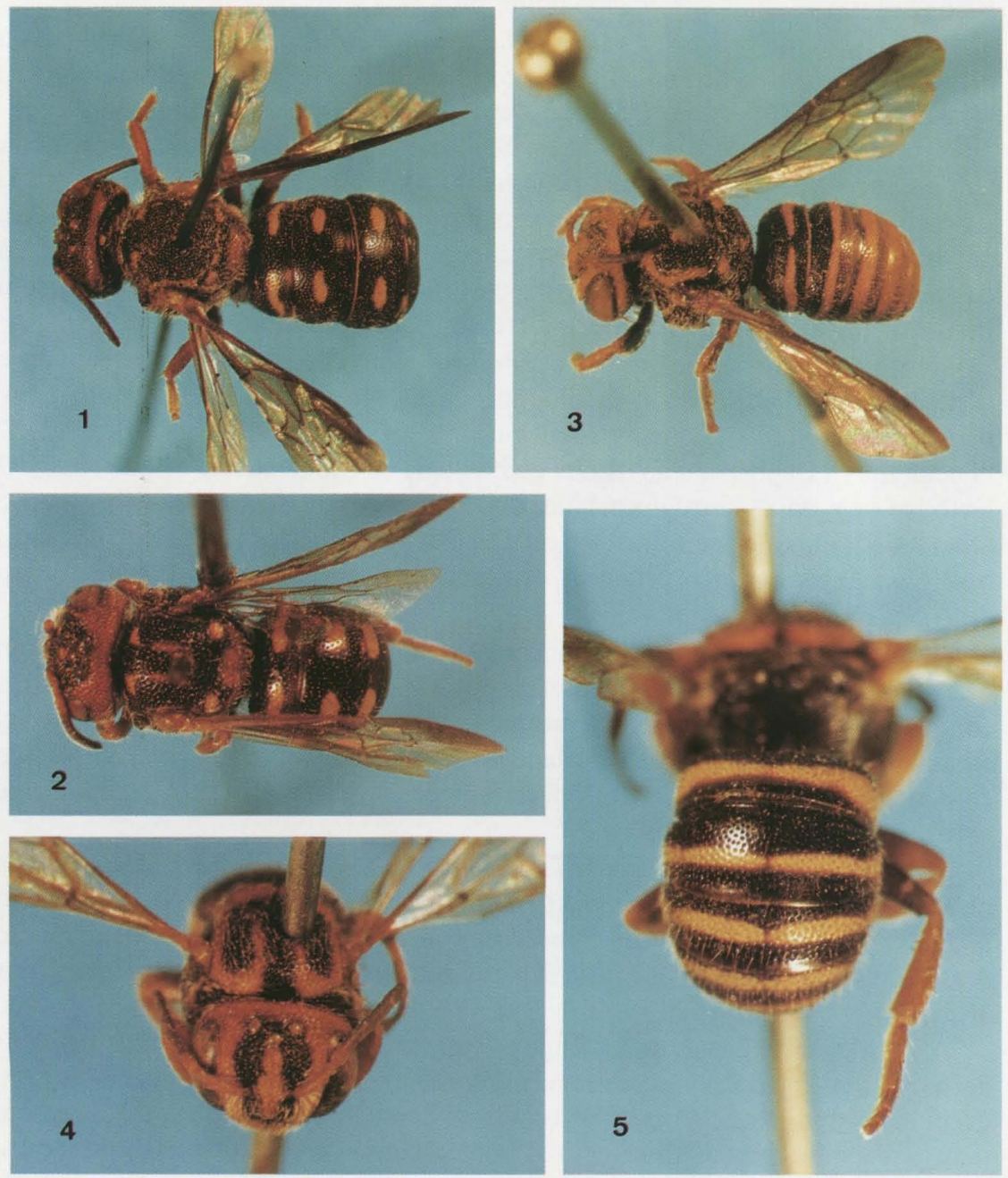

5

Figs 1-5. Exemplares-tipos das espécies de Austrostelis: 1) Dianthidium nudum, lectótipo fêmea; 2) Dianthidium catamarcense, lectótipo macho; 3) Dianthidium iheringi, lectótipo macho; 4-5) Dianthidium zebratum, lectótipo macho. 
Distribuição geográfica. BRASIL: Minas Gerais, Passos; Goiás, S. Domingos; São Paulo, Jundiaí; Rio Grande do Sul, Guaíba. Argentina: Tucumán, La Rioja, Buenos Aires, Catamarca. PARAGUAI: San Bernardino.

\section{Austrostelis iheringi (Schrottky, 1910) comb.n.}

Fig. 3

Dianthidium iheringi Schrottky, 1910: 270.

Stelis iheringi Friese, 1925: 38. - Michener \& Griswold, 1994: 677; syn.

Hoplostelis (Austrostelis) iheringi; Michener \& Griswold, 1994: 677.

Stelis iheringi Friese, 1925, por ser um sinônimo de Dianthidium iheringi Schrottky, 1910, tornou-se homônimo, dentro de Austrostelis.

Diagnose. Cabeça amarela, com duas largas estrias pretas entre as paroculares e a fronte, mais largas dorsalmente, unidas à estreita faixa preta do vértice que se estende até os olhos; genas com faixa amarela justaorbital, pretas na metade posterior. Mesoscuto preto com máculas amarelas em J ou em U invertidos; escutelo e axilas com nódoas amarelas. Tergos pretos com faixas discais amarelas. Macho com o sexto tergo pouco menor que o anterior; sétimo protuberante no disco, sem tubérculos laterais; terceiro e quarto esternos com franja decumbente muito longa e encurvada para o meio nos flancos.

Lectótipo macho de Dianthidium iheringi, aqui designado, com as etiquetas: "18.109" "círculo azul" "Dianthidium/iheringi n.sp/C. Schrottky det. 1910/type" "102.253" "Dianthid./ iheringi Schrottky / Jundiahy (Est. S.P.) / Ducke rev. 13" "Lectotypus". Está depositado na Coleção do Museu de Zoologia da Universidade de São Paulo. O espécimen tem faixa amarela em todos os tergos, muito larga do terceiro ao sétimo e a margem translúcida amarelo-palha do segundo ao quinto; pernas pretas com manchas amarelas.

Variações. Espécimens coletados em Nova Teutônia (Seara), Santa Catarina, com as máculas do mesoscuto em J ou U invertido, ou ainda com o ramo discal da nódoa até o meio do esclerito. Fêmeas com faixas castanho-amareladas em vez de amarelas nos tergos, clípeo preto com faixa amarela discal ou com o amarelo deixando a margem e duas nódoas látero-basais pretas, ou ainda com a faixa amarela interrompida; sexto tergo preto ou com duas manchas largas amarelas aos lados; mesepisternos pretos, com nódoa amarela reduzida ou com mancha amarela grande, e uma menor nos metepisternos. Uma fêmea, coletada em Viçosa, Minas Gerais, com faixa amarela larga no sexto tergo.

Machos, coletados em Seara com o clípeo quase todo amarelo com ou sem nódoas basais pretas e borda preta; terceiro e quarto ou o quarto e quinto tergos com margem amarelo-acastanhada translúcida, ou ainda todos os tergos pretos sem margem translúcida pálida; segundo esterno preto ou com grandes áreas laterais amarelas. Um macho, de Maracás, Bahia, com muito amarelo-pálido nas pernas, nos lados e na parte ventral dos mesepisternos e o segundo esterno inteiramente amarelo-pálido.

Distribuição geográfica. BRASIL: Bahia, Maracás; Minas Gerais, Viçosa; Rio de Janeiro, Represa Rio Grande; Paraná, Curitiba; Santa Catarina, Seara (Nova Teutônia); São Paulo, Jundiaí. 


\section{Austrostelis zebrata (Schrottky, 1905) comb.n.}

Figs 4-5

Dianthidium zebratum Schrottky, 1905: 7.

Hoplostelis (Austrostelis) zebrata; Michener \& Griswold, 1994: 677.

Diagnose. Tegumento preto com desenhos amarelo-ferrugíneos na cabeça e mesosoma. Na cabeça, grande nódoa preta em U invertido, dos cantos da sutura epistomal aos alvéolos e destes à área ocelar. Mesoscuto com máculas amarelo-ferrugíneas em $U$ invertido; escutelo amarelo-ferrugíneo. Tergos pretos com faixas discais amarelas. Tergos distais do macho e terceiro e quarto esternos como em $A$. iheringi.

Lectótipo macho, aqui designado, com as seguintes etiquetas: "Encarnacion / Paraguay / II. 1905 / C. Schrottky" "Dianthidium / zebratum / ô Schrottky" "102.252" "Stelis / zebrata / Schr. / Det. J.S. Moure 1957" "Lectotypus". Está depositado no Museu de Zoologia da Universidade de São Paulo. Tem desenhos amarelos e ferrugíneos na cabeça e no mesosoma; clípeo amarelo com pequena área ferrugínea orlada com preto junto à sutura epistomal; estria amarelo-ferrugínea no meio da fronte incluindo a área supraclipeal; estria pós-ocelar e as genais ferrugíneas; mesepisternos com grande nódoa ferrugínea; mesoscuto com máculas ferrugíneas em U invertido com pequena área amarela basal; primeiro ao sexto tergo com faixa discal amarela estreita; sétimo tergo castanho, em arco rebaixado.

Variações. Foi vista uma fêmea, coletada em Rio Claro, São Paulo, com as faixas amarelas dos tergos muito finas e interrompidas, as do quarto e quinto tergos mais finas que as outras.

Entre os machos coletados em Misiones, Argentina, foram vistos exemplares com o tegumento claro na cabeça, ferrugíneo e amarelo-ferrugíneo, o preto limitado ao topo da cabeça; o mesoscuto com as máculas em U invertido preenchidas com ferrugíneo-acastanhado, em um exemplar as duas máculas em $\mathrm{U}$ unidas posteriormente por larga área ferrugínea; com as faixas amarelas dos tergos recortadas nos flancos, fragmentadas nos lados e no meio ou só nos lados.

Distribuição geográfica. BRAsIL: Mato Grosso, Cáceres, São Paulo, Rio Claro. ARGENTINA: Misiones. PARAGUAI: Itapoá, Encarnación.

\section{Chave para as espécies de Austrostelis}

1. Segundo ao quarto tergo com quatro séries de nódoas amarelas arredondadas. Sétimo tergo do macho com dois tubérculos laterais carenados, resultando um aspecto bissinuoso ...................... catamarcensis

1'. Segundo ao quarto tergo com faixa amarela discal. Sétimo tergo do macho em arco rebaixado, sem tubérculos ........................ 2

2. Cabeça e mesosoma com desenhos amarelos................. iheringi

2'. Cabeça e mesosoma com desenhos ferrugíneos; cabeça com amarelo-ferrugíneo nas paroculares e no meio da fronte. ................. zebrata trabalho e ao Prof. Dr. Jesus S. Moure pelo acesso às notas sobre os tipos de abelhas. 


\section{REFERÊNCIAS BIBLIOGRÁFICAS}

Cockerell, T.D.A. 1919. New and little-known American Bees. Can. Ent. 51: 26-28.

FRIESE, H. 1925. Neue Formen von Schmarotzerbienen, besonders aus dem paläarktischen Gebiet. Konovia 4: 27-42.

GRISWOLD, T.L. \& C.D. MiCHENER. 1988. Taxonomic observations on Anthidiini of the Western Hemisphere (Hymenoptera: Megachilidae). Jour. Kansas Ent. Soc. 61 (1): 22-45.

MicheNER, C.D. \& T.L. GRISWolD. 1994. The Neotropical Stelis-like cleptoparasitic bees (Hymenoptera: Megachilidae). Proc. Entomol. Soc. Wash. 96 (4): 674-678.

MoURE, J.S. \& D. URBAN. 1994. Rhynostelis, gen. n. e notas sobre Hoplostelis Dominique (Hymenoptera, Apoidea, Megachilidae). Revta bras. Zool. 11 (2): 297-302.

SCHROTtKy, C. 1905. Al conocimiento de los Himenópteros del Paraguay. An. Ci. Paraguayos 4 (1): 1-14.

- 1909a. Hymenoptera nova. An. Soc. Ci. Argentina 67: 209-228.

. 1909b. Himenópteros de Catamarca An. Soc. Ci. Argentina 68: 233-272. 1910. Neue südamerikanische Arten der Bienengattung Anthidium Fabr.

Wien. Ent. Ztg. 29: 267-271.

Recebido em 08.X.1998; aceito em 24.VI.1999. 